\title{
Type of broadleaf forest matters most for ptyctimous mite communities (Acari, Oribatida) in Norway
}

\author{
Anna Seniczak ${ }^{1}$ (D) Wojciech Niedbała ${ }^{2,3}$. J. Carlos Iturrondobeitia ${ }^{4}$. \\ Stanisław Seniczak ${ }^{5}$. Steffen Roth ${ }^{1} \cdot$ Bjarte H. Jordal $^{1}$
}

Received: 15 December 2020 / Revised: 25 May 2021 / Accepted: 26 June 2021 /

Published online: 11 July 2021

(c) The Author(s) 2021

\begin{abstract}
We studied ptyctimous moss mites, which are characteristic of forest habitats, in Norwegian broadleaf forests considered as biodiversity hotspot areas in Fennoscandia. The study aimed to evaluate the effect of different factors (regional locality, annual precipitation, mean annual temperature, forest type, forest wetness and microhabitat) on the ptyctimous mites and on discovering their richness in broadleaf forests. Samples were collected from nine broadleaf forests in Western, Southern and Eastern Norway, in different climatic conditions, six forest types, three forest wetness states and eight microhabitats. Overall, 3341 ptyctimous mites were collected and their abundance differed significantly among the regions, forest types and microhabitats. Forest type turned out to be the most important factor, responsible for $24.5 \%$ of the total variation in the abundance of the ptyctimous mites. Other important factors were forest wetness and microhabitat. In total, 27 species, i.e., $87 \%$ of all ptyctimous mites known from before in Norway were found and the species richness was highest in the east and lowest in the west of the country. Atropacarus (Atropacarus) striculus was most common and most abundant; it made nearly $30 \%$ of all ptyctimous mites collected. On the other hand, a quarter of the species were represented by less than 10 specimens; most of these were new records for Norway. Among ten species discovered as new to Norway, four were also new to Fennoscandia. These findings confirm the unique character and high biological diversity of Norwegian broadleaf forests.
\end{abstract}

Communicated by P. Ponel.

Anna Seniczak

Anna.Seniczak@uib.no

1 Department of Natural History, University Museum of Bergen, University of Bergen, Bergen, Norway

2 Department of Animal Taxonomy and Ecology, Faculty of Biology, Adam Mickiewicz University, Poznan, Poland

3 Natural History Collections, Faculty of Biology, Adam Mickiewicz University, Poznan, Poland

4 Department of Zoology and Cellular Animal Biology, University of the Basque Country, Bizkaia, Spain

5 Department of Evolutionary Biology, Faculty of Biological Sciences, Kazimierz Wielki University, Bydgoszcz, Poland 
Keywords Box mites $\cdot$ Moss mites $\cdot$ Forest habitats $\cdot$ New species records $\cdot$ Fennoscandia

\section{Introduction}

Broadleaf forests are rare in Norway. They cover only about $22,000 \mathrm{~km}^{2}$, i.e., only $17 \%$ of all forests and slightly less than $6 \%$ of the area of Norway (Norwegian Ministry of the Environment 2011). They are located along the western and southern coasts, where there is high precipitation and winters are relatively warm. Many of them remain in pristine conditions and are considered the most biodiverse terrestrial habitats in Fennoscandia (Håpnes 2003). Mites are no exceptions and 15 records of oribatid mites new for Norway have been recently found just in one broadleaf forest (Seniczak et al. 2019a), whereas ten new records of mesostigmatid mites were reported from two broadleaf forests (Bolger et al. 2018), all in Western Norway. This high number of new records is also partially related to the fact that the acarofauna of broadleaf forests is poorly studied, both in Norway and in Fennoscandia (Huhta et al. 2005), and most acarological studies in Norway have focused on coniferous forests (e.g., Hågvar 1998; Hågvar and Amundsen 1981; Thunes et al. 2003, 2004; for more references see Seniczak et al. 2019a).

Ptyctimous mites belong to suborder Oribatida and can be easily recognized by their peculiar body shape and ability to encapsulate themselves (Fig. 1), the phenomenon called the ptychoidy from which the common name- 'box mites', comes from. Ptychoidy has evolved at least three times during the evolution (Sanders and Norton 2004), so ptyctimous mites form a heterogeneous group which belongs to two separate supercohorts: Enarthronotides (Protoplophoridae and Mesoplophoridae) and Mixonomatides (Euphthiracaroidea and Phthiracaroidea) (Niedbała and Liu 2018).

These mites are important component of the forest acarofauna. Although they are usually not the most abundant group, with only about $2-7 \%$ of the total number of Oribatida (Niedbała 1992), they are ecologically important and species-rich in forest habitats (Niedbała et al. 2020). All life stages of ptyctimous mites are saprophagous, i.e., they feed on dead organic matter, playing an important role in the mechanical breakdown of decaying litter, contributing to humification processes, and helping in accumulation of nutrients for plants. Due to their poor mobility their contribution to fungal spore dissemination is rather insignificant (Pande and Berthet 1973). Immature stages form galleries inside dead wood or conifer needles and never leave them. They cannot be extracted with quick methods
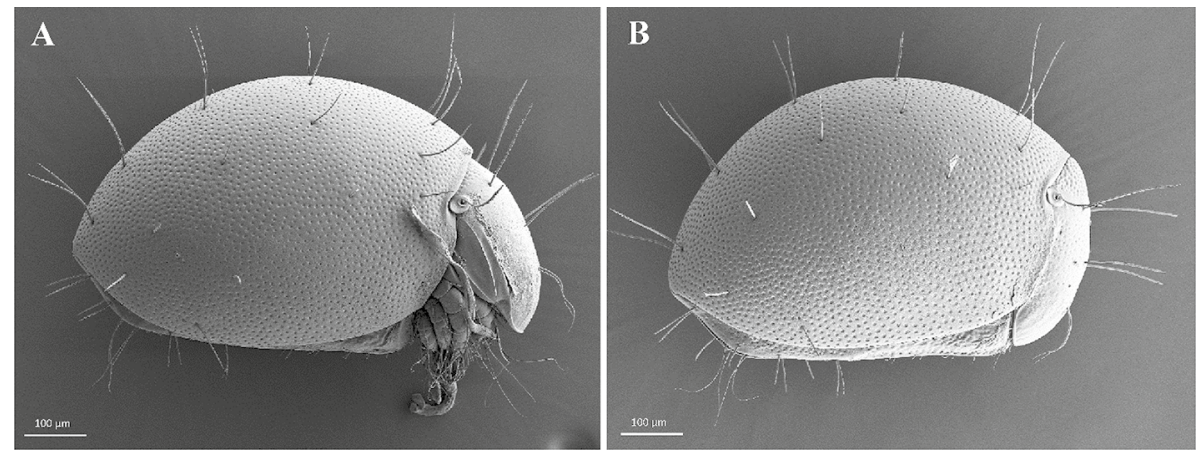

Fig. 1 Ptyctimous mite, Euphthiracarus cribrarius, lateral view: A legs visible, B encapsulated state 
based on drying of the substrate (e.g., Berlese or Tullgren apparatus), because they die inside their galleries during the extraction process. These stages can only be obtained by dissecting dead wood or conifer needles (Niedbała 1992; Hågvar 1998).

The world of ptyctimous mites comprises 1,431 described species (Niedbała and Liu 2018), i.e., 13\% of 11,325 species of Oribatida (without Astigmata) (Subías 2004, 2021). In Norway 21 ptyctimous species have been recorded (Niedbała and Liu 2018; Seniczak et al. 2019a, c) that accounts for about 7\% of all Oribatida known in Norway (Seniczak et al. 2019a). Most studies on ptyctimous mites focus on taxonomy and geographical distribution, while very little is known about their biology and ecology (Niedbała et al. 2020). It is mostly due to the fact that this group is taxonomically difficult: the number of diagnostic features is small, descriptions of species are usually incomplete, and it is often difficult or even impossible to identify species with published keys (Niedbała 2008). Habitat preferences have been summarized for ptyctimous mites in Poland (Niedbała 2008; Niedbała et al. 2020), Finland (Penttinen and Huhta 2009), and Germany (Beck et al. 2014; Weigmann et al. 2015) where they also included some microhabitats of broadleaf forests.

This study aimed to evaluate the effect of different factors: regional locality (Western, Southern and Eastern Norway), annual precipitation, mean annual temperature, forest type, forest wetness, and forest microhabitat on the ptyctimous communities, as well as to discover the richness of these mites in Norwegian broadleaf forests.

\section{Materials and methods}

\section{Study sites}

Samples were collected in nine broadleaf forests (Fig. 2). Two of them were located in Western Norway (Neshalvøya-referred later as W1 and Kolneset-referred as W2), five in Southern Norway (Leirvik—S1, Søyland—S2, Verpåsen-S3, Solvang—S4, and

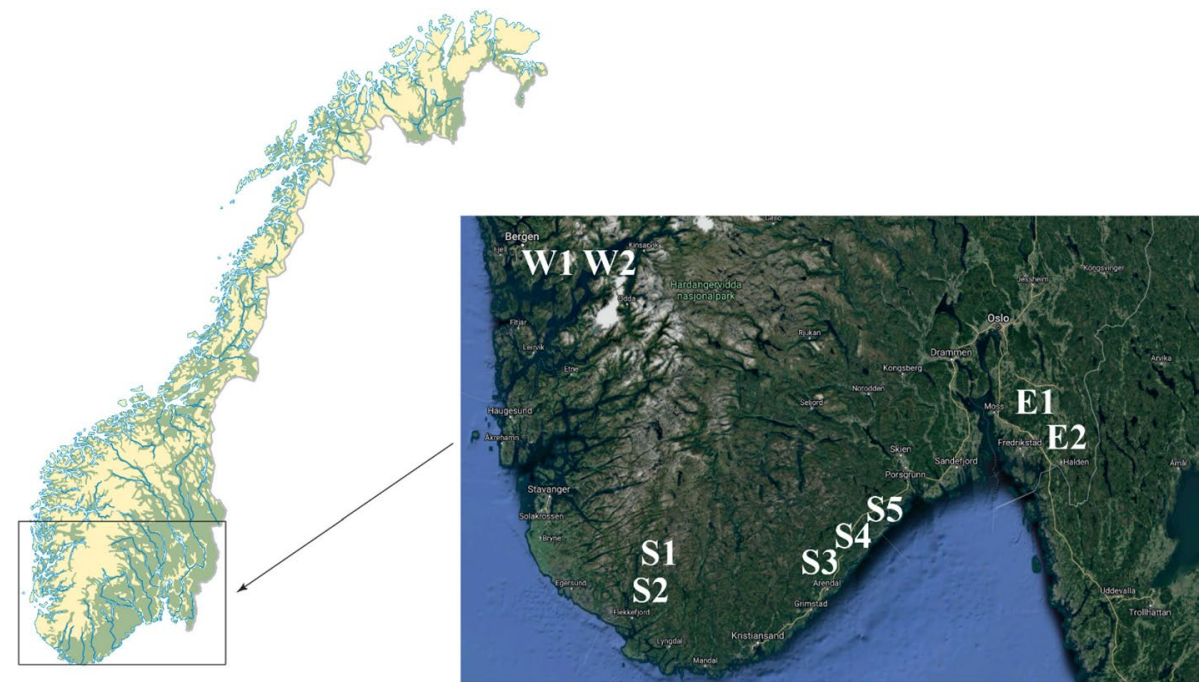

Fig. 2 Location of the studied broadleaf forests in Norway: western (W1 and W2), southern (S1-S5), and eastern part (E1 and E2) ( modified from https://www.norgeskart.no) 

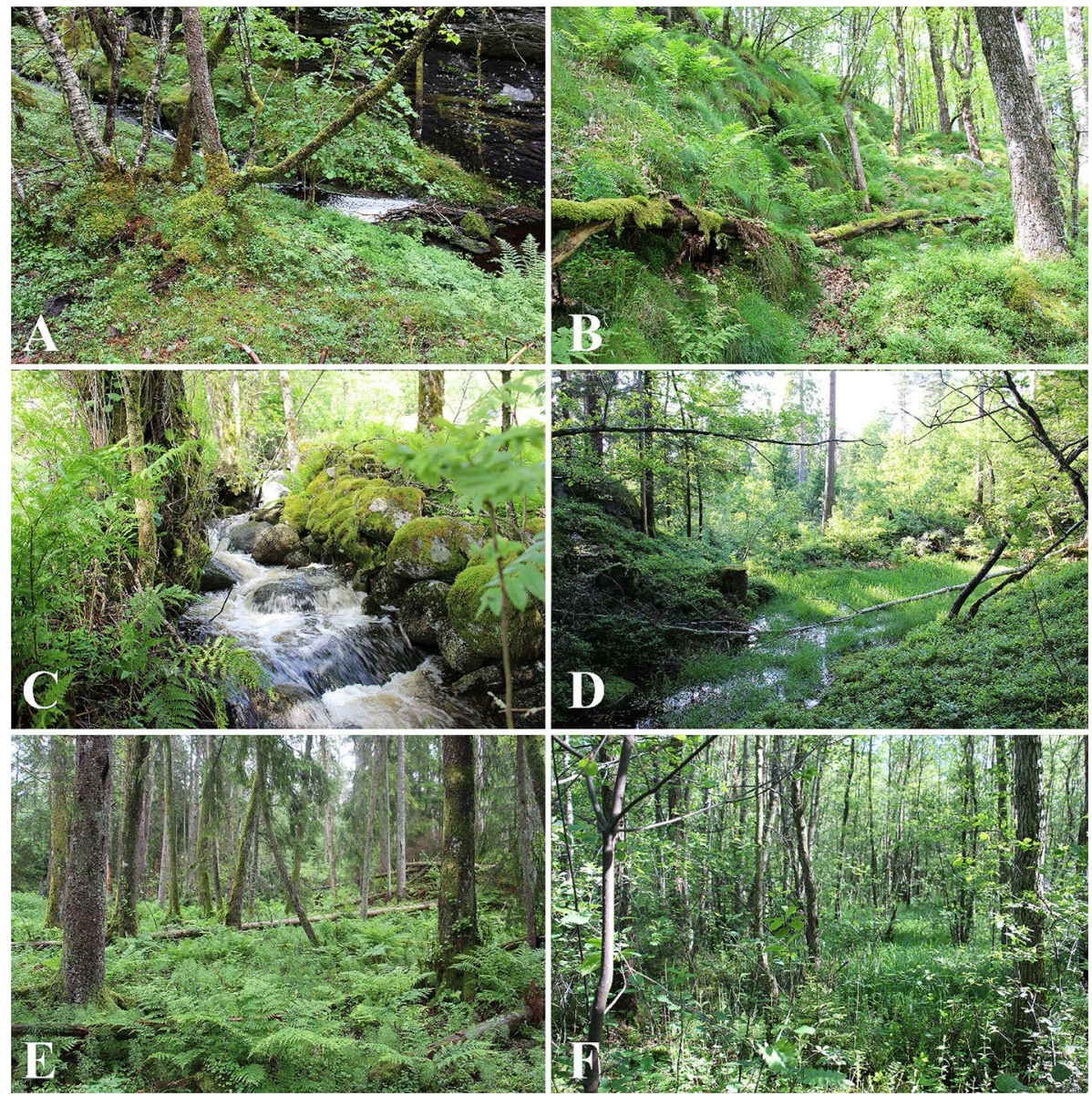

Fig. 3 Studied types of broadleaf forests in Norway: A mixture of low-herb broadleaf and riparian forest (W1); B rich broadleaf forest (S2); C swamp (S1); D limestone forest (S3); E marsh (S4); F old swamp (E2)

Stamsøy-S5) and two others, in eastern part of the country (Kjeøya-E1 and OpstadE2). They were categorized to six different forest types (Fig. 3). One of these types (a rich broadleaf forest) was represented by four forests, each located in a different vegetation zone. All study sites were characterized by an oceanic climate but differed in the temperature and precipitation (Table 1).

The sampling areas in Western Norway have high precipitation, relatively cool summer (10-15 ${ }^{\circ} \mathrm{C}$ in July and August) and mild winter (with average temperature in the coldest month, February $-2{ }^{\circ} \mathrm{C}$, Holtan 2009). The study site W1 was situated close to a stream floating along small vertical rock formations, where the bedrock consisted mainly of schist and some alkaline rocks. The most abundant trees and bushes were hazel (Corylus avellana), ash (Fraxinus excelsior), lime (Tilia cordata), grey alder (Alnus incana), birch (Betula pendula), and rowan (Sorbus aucuparia). The forest floor was overgrown by mosses, ferns and several herb species, with dominant sweetscented bedstraw (Galium odoratum). Fallen dead wood with mosses were frequent at the site. The other site, W2, was a steep 


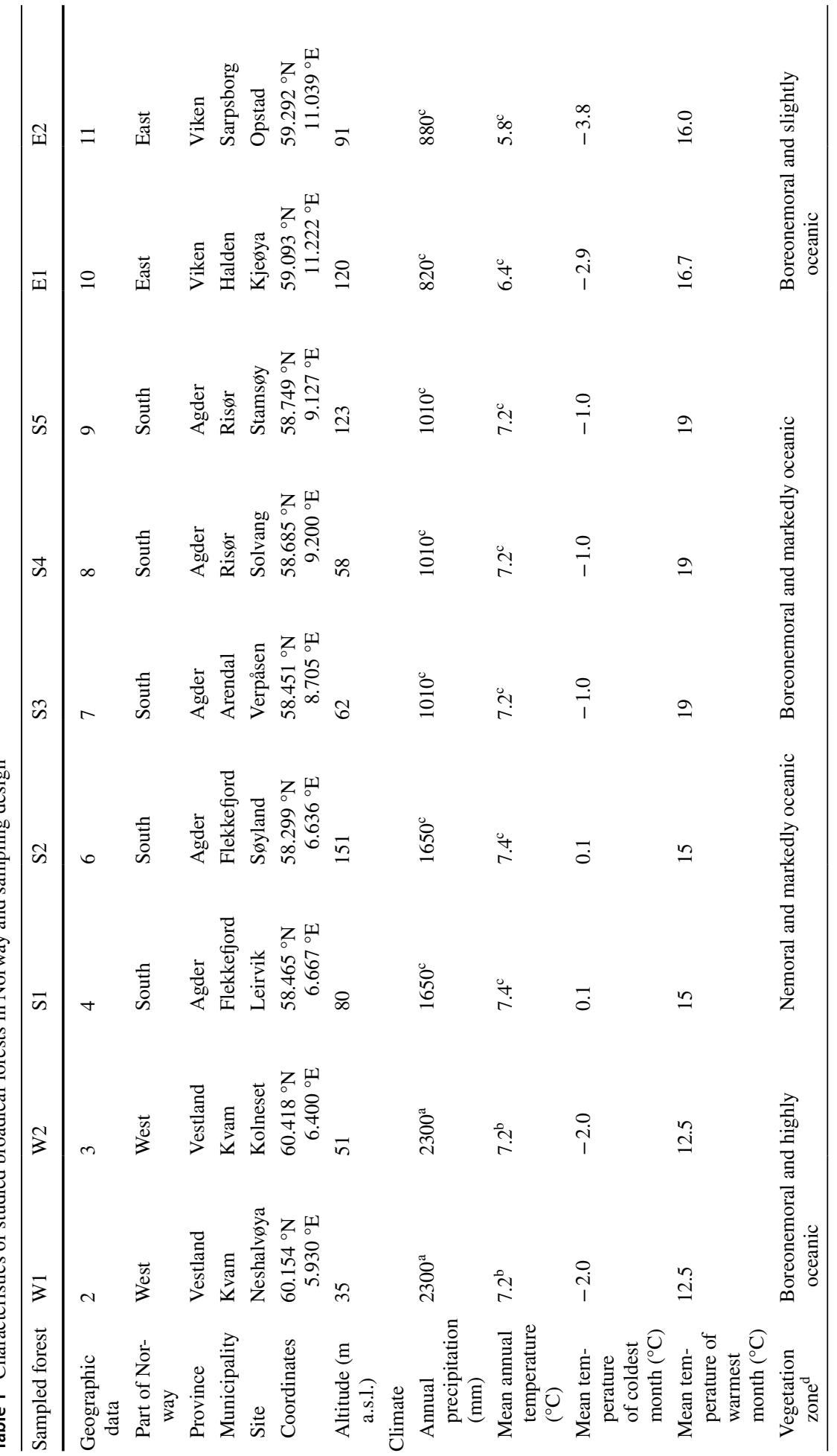




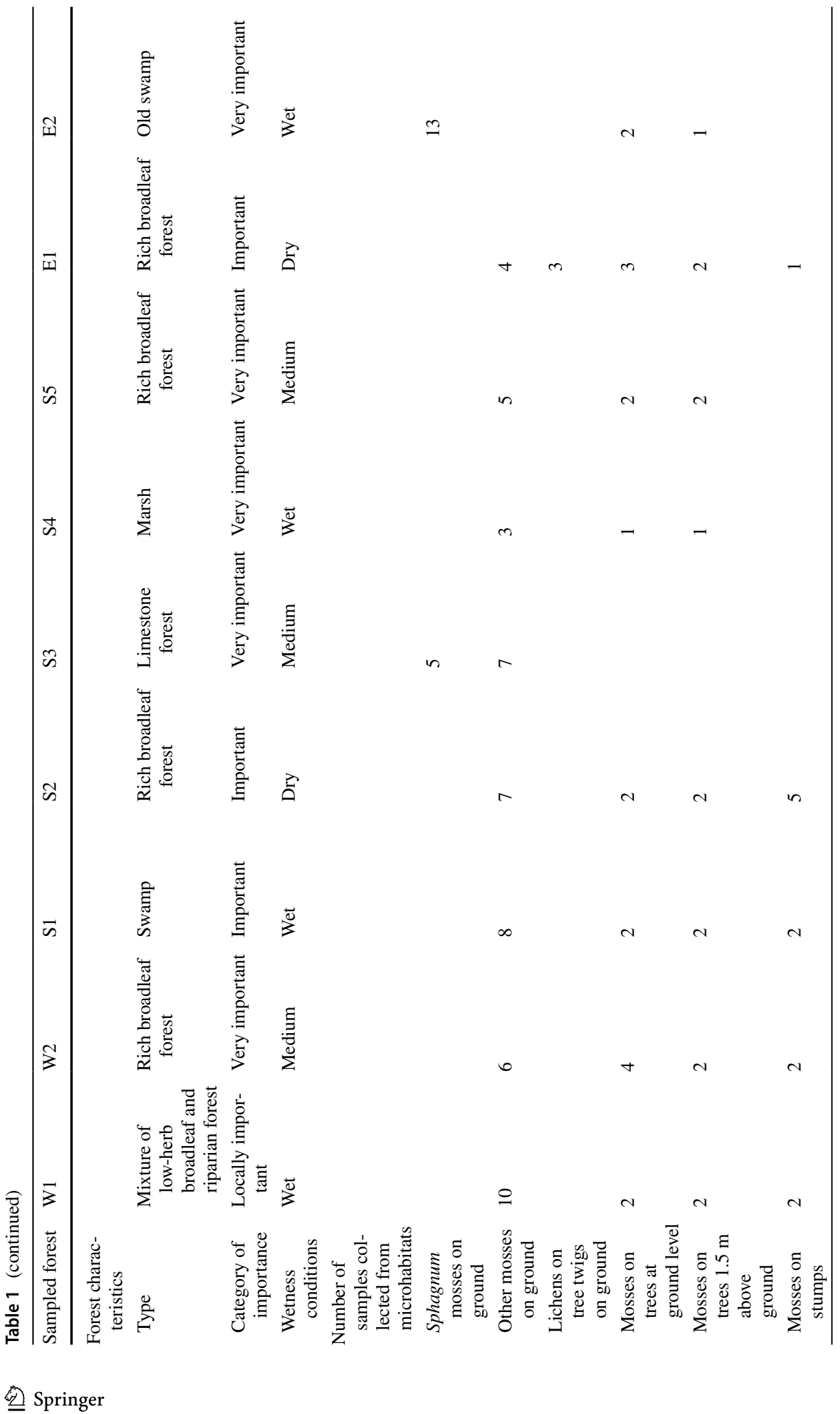




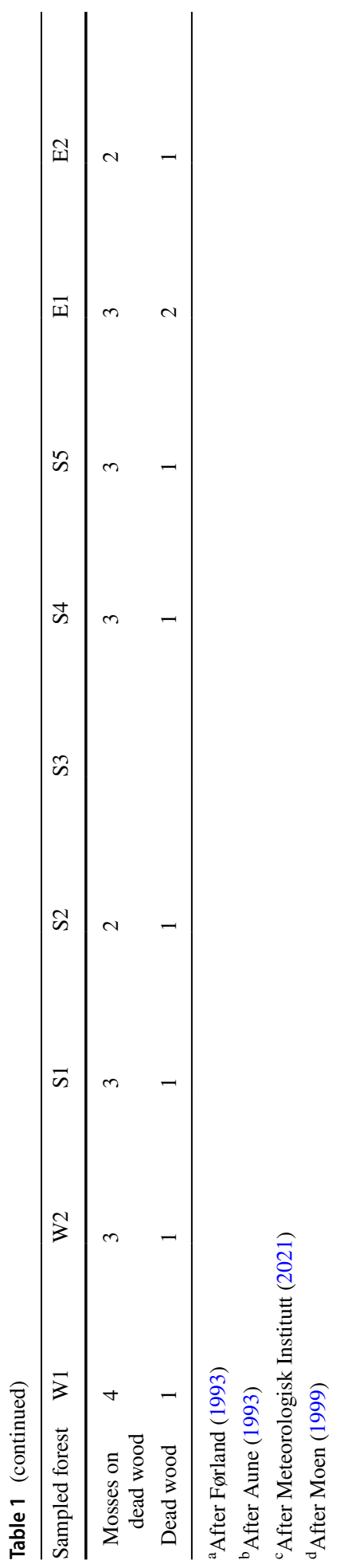


and east-exposed slope with small dry ridges. The bedrock consisted mainly of different types of gneiss, with the loose masses of weathering material. The forest belonged to an unusual type of habitat, a low-herb broadleaf forest with little historical disturbance. The forest was dominated by tree species such as oak (mostly Quercus robur), lime, Scots pine (Pinus sylvestris), ash, hazel, aspen (Populus tremula), and guelder rose (Viburnum opu$l u s$ ). The ground vegetation was scattered and dominated by habitat-specific plants, e.g., mountain melick (Melica nutans), sticky catchfly (Lychnis viscaria), angular Solomon's seal (Polygonatum odoratum), and mosses. Moreover, the occurrence of some old trees and dead wood characterized the sampling site. The presence of some creeping soft grass (Holcus mollis) and pollarded lime trees indicated former grazing and pruning activities, respectively.

Two forests in Southern Norway (S1 and S2) had slightly warmer summer (about $15{ }^{\circ} \mathrm{C}$ in July and August) and winter (around $0.1{ }^{\circ} \mathrm{C}$ in the coldest month-February), comparing to Western Norway. The area was dominated by poor bedrock and consisted of acidic and hard rocks (such as granite, gneiss, amphibolite). The terrain was heavily hilly with many rivers and small valleys. One of the forests, S1, was a swamp dominated by common alder (Alnus glutinosa), with some old oaks in inner parts, and a sandy beach on the lake. The other sampling site, S2, was a rich and dry broadleaf forest. It occupied south and west-south slope overgrown by oak, hazel, ash, birch, rowan and sycamore maple (Acer pseudoplatanus).

Three other sampling sites (S3-S5) had relatively warm summer (around $19{ }^{\circ} \mathrm{C}$ in July and August) and winter (around $-1.0^{\circ} \mathrm{C}$ in February). The sampling site S3 belonged to the southeastern Norwegian bedrock area, which consisted mainly of gneiss with a district direction southwest-northeast, parallel to the coast, but also some granite. It was situated on an amphibolite ridge with heterogeneous terrain (hilly, rock walls, stone blocks, lime rich patches) and a small valley along the stream. The geology in sampling sites S4 and S5 was very variable, spanning both nutrient-rich (easy-to-soluble) shale rocks and hard and acidic rocks such as granite and gneiss. Forest S3 was dominated by spruce (Picea abies) with enclosure oak trees and a strong mosaic patterns related to nutritional and lime-richness. Rich parts were otherwise characterized by large hazels. The herb layer was speciesrich with several red-list species in high categories. Forest S4 was a large and relatively intact marsh forest with both, older trees and rich lots. The site was characterized by a mosaic of internal topography and many large and small swamps between small shrubs and rocks. Dominant tree species were common alder and spruce, but also ash, birch and pine occurred. Oak, asp, hazelnut, rowan and juniper grew on the edge. The herb layer was dominated by lady fern (Athyrium filix-femina), sedges, wood millet (Milium effusum) and several plant species that are indicators of wet habitats. Forest S5 was species-rich, intact and heterogeneous, dominated by partly very old oaks, lime, ash, maple, aspen, field elm (Ulmus minor), hazel, wild cherry (Prunus avium), willows (Salix spp.) and pine. The site consisted of east- or south-facing slopes and hilly areas cut by cracks. The bedrock was mainly gneiss bands with amphibolite passages. The herb and shrub vegetation were species-rich, both in drier and wetter parts, and included European blueberry (Vaccinium myrtillus), liverwort (Anemone hepatica), sweet-scented bedstraw (Galium odoratum), lily of the valley (Convallaria majalis), wood club-rush (Scirpus sylvaticus), meadowsweet (Filipendula ulmaria), and broad buckler-fern (Dryopteris dilatata).

Two sampling sites in Eastern Norway (E1 and E2) had relatively mild summer, with average temperatures between 16.0 and $16.7^{\circ} \mathrm{C}$ in July and August. Winter was slightly colder than in the other study sites; in the coldest months (January and February) the average temperatures were around -2.9 and $-3.8{ }^{\circ} \mathrm{C}$. The sampling sites were located in the 
south-eastern Norwegian bedrock area, which consisted mainly of gneiss and granite rocks of different composition. Forest E1 was characterized by old and large oak and lime trees. Other tree species were hazel, ash, Norway maple (Acer platanoides), and with some spruce and pine addition. The herb vegetation was partly sparse. The site E2 was a mixture of spring swamps and swamp forests. The natural basis were marine deposits, silt and clay with source springs that keep the forest floor moist. The dominant tree species was common alder, the shrub and herb layer had barberry (Berberis vulgaris), common cottongrass (Eriophorum angustifolium), rough horsetail (Equisetum hyemale) and different sedge species.

\section{Sampling and identification}

A total of 147 samples, each of a volume of $500 \mathrm{~cm}^{3}$, were collected by hand between 8th and 12th June 2017 from the nine broadleaf forests and several microhabitats: (1) Sphagnum mosses on ground (18 samples), (2) other mosses on ground (49 samples), (3) lichens on tree twigs lying on ground ( 3 samples), (4) mosses on tree trunks on ground level (18 samples), (5) mosses on tree trunks $1.5 \mathrm{~m}$ above ground (14 samples), (6) mosses on stumps (13 samples), (7) mosses on dead wood (23 samples), and (8) dead wood (9 samples). Different number of samples from microhabitats was caused by the fact, that not in all forests all microhabitats could be found.

Adult mites were extracted using Tullgren funnels for 14 days and preserved in $90 \%$ ethanol. Ptyctimous mites were sorted out from the samples under stereomicroscope, mounted on slides in lactic acid and identified mainly by W. Niedbała according to the keys (Niedbała 2008, 2011). All species are deposited at the University Museum of Bergen, Norway, while some duplicates are donated to W. Niedbała (Adam Mickiewicz University, Poznań, Poland). Data on other oribatid mites present in the samples will be published later.

The systematics, nomenclature and global distribution of mites follow Niedbała and Liu (2018). Habitat preferences of species (Table 2) are based on Beck et al. (2014), Schatz (2015) and Weigmann et al. (2015). They include the following types: alpine, subalpine, hygrophilous (living in wet places), mesohygrophilous (species which prefer high moisture but not wet places), xerophilous (living in dry places), arboricolous (living on trees), epilithic (living on rocks, stones, walls), geophilous (living in soil), lichenicolous (living on lichens), muscicolous (living in mosses), praticolous (meadow species), silvicolous (forest species), tyrphophilous (bog species), xylophilous (living in wood) and eurytopic (occurring in more than three habitat types). The new records of Oribatida for Fennoscandia are based on Niedbała and Liu (2018) and those for Norway are based on Niedbała and Liu (2018), and Seniczak et al. (2019a, c).

The classes of dominance $(D)$, i.e., percentage of specimens of a particular species among ptyctimous mites in particular forest follow Seniczak (1978), including superdominants which are characteristic of extreme microhabitats (Table 3), and classes of frequency $(C)$, i.e., percentage of samples in particular forest where the species was found (Table 4) follow Górny and Grüm (1981). Categories summarizing the status of occurrence of ptyctimous species (Table 6) follow Niedbała et al. (2020). 


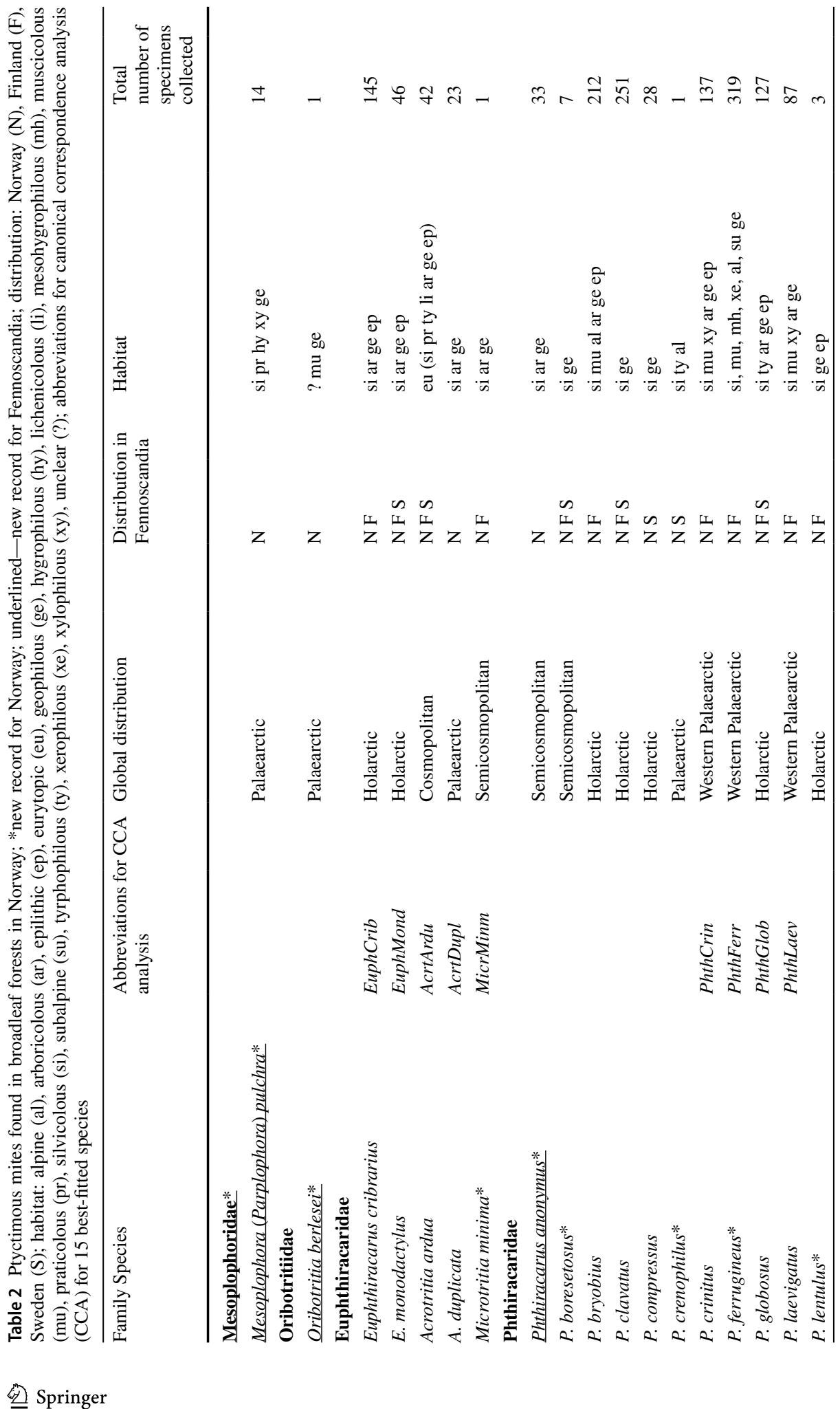




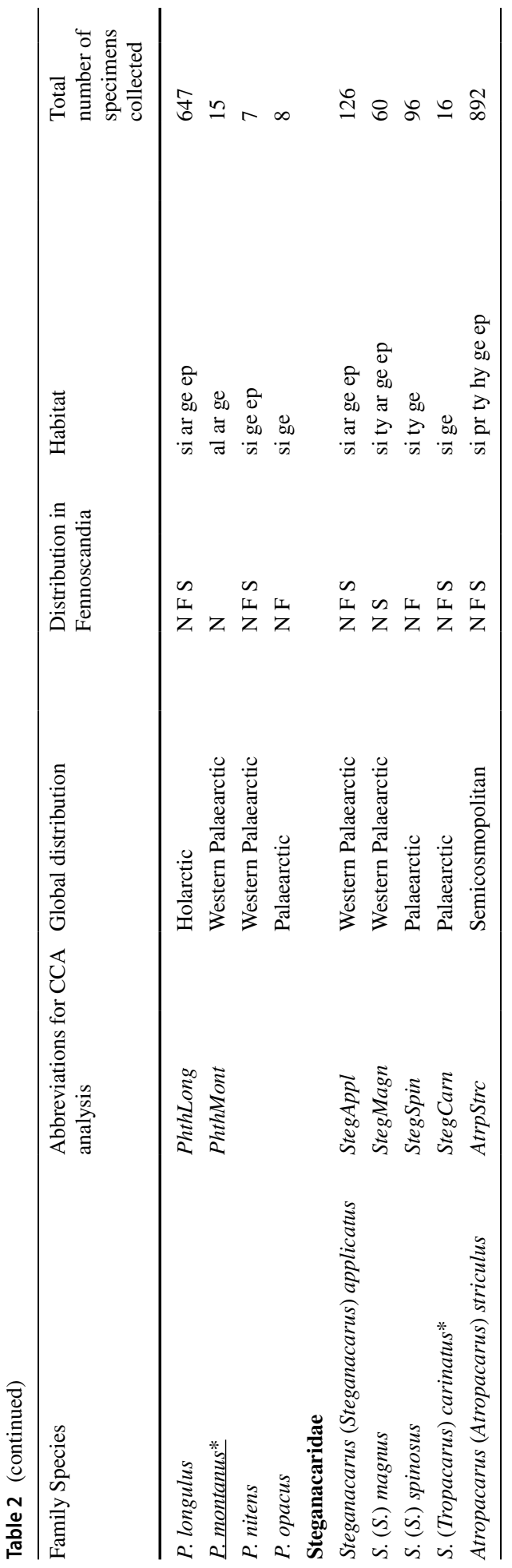




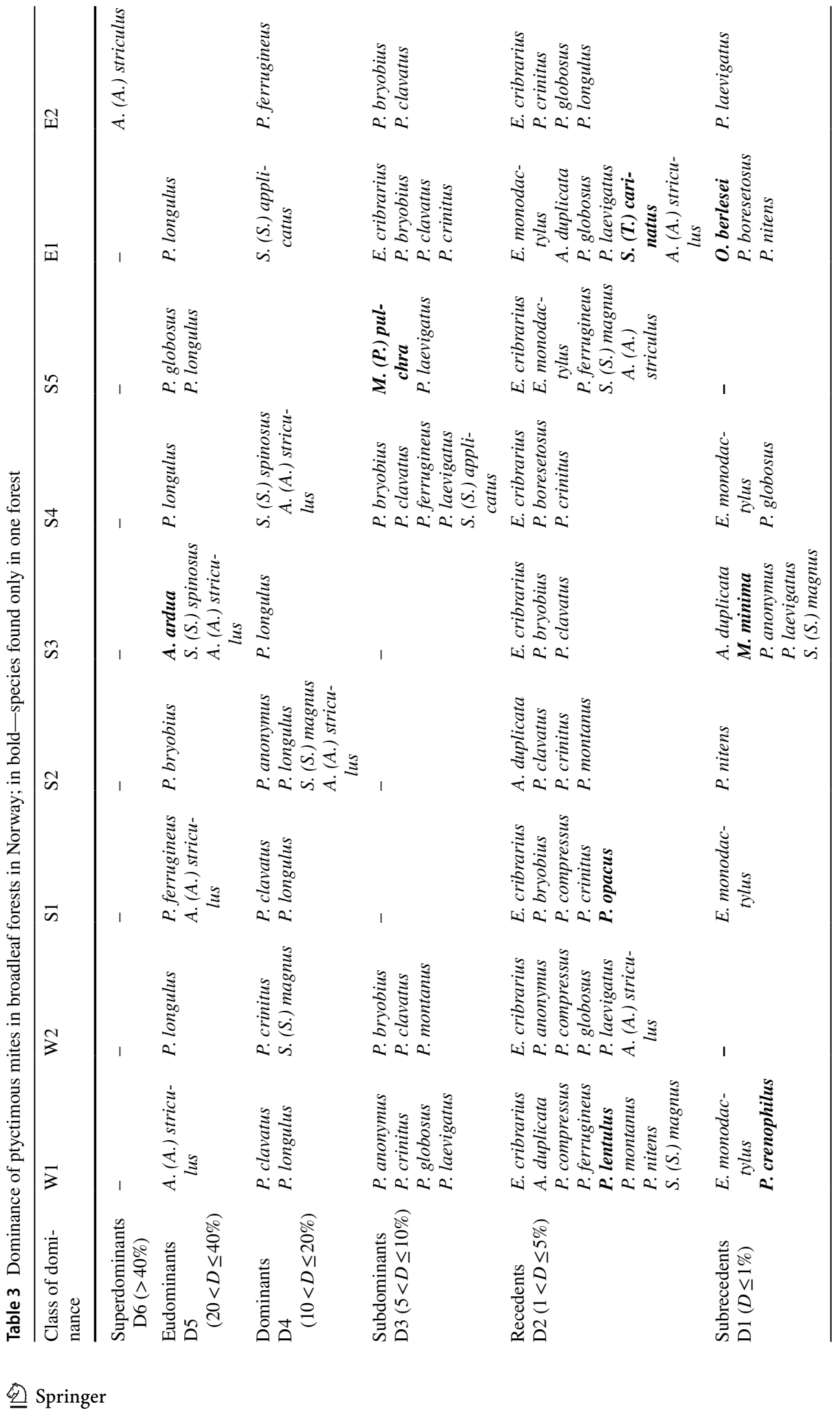




\section{Statistical analyses}

The ptyctimous communities were characterized by the abundance index (ind. $.500 \mathrm{~cm}^{3}$ ) and species richness (number of species per sample). Normality of the distribution was tested with Kolmogorov-Smirnov test, while equality of variance in different samples with Levene test. The assumption of normality or equality of variance was not met, so the nonparametric Kruskal-Wallis test by ranks was used, and in case of significant differences between medians, a multiple comparison test between mean ranks was applied. These calculations were carried out with STATISTICA12.5 software.

All multivariate analyses were performed using CANOCO software (Microcomputer Power, Ithaca, NY, USA; Ter Braak 1988; Jongman et al. 1995). Response data or dependent variables (abundance of ptyctimous species) were log-transformed, log $(x+1)$ (Łomnicki 2010), considering the down-weighting of rare species. Independent or explanatory variables were: region (Western, Southern, Eastern), annual precipitation (820-2300 mm), mean annual temperature $\left(5.8-7.4{ }^{\circ} \mathrm{C}\right)$, forest (W1, W2, S1, S2, S3, S4, S5, E1, E2), forest wetness (dry, medium, wet), microhabitat (Sphagnum mosses on ground, other mosses on ground, lichens on tree twigs lying on ground, mosses on trees at ground level, mosses on trees $1.5 \mathrm{~m}$ above ground, mosses on stumps, mosses on dead wood, and dead wood), all taken as factors or dummies.

First, we checked using canonical correspondence analysis (CCA) if any of the independent variables, when treated separately, explained the variation of ptyctimous communities (simple effects). Next, they were compared to conditional effects of the same independent variables to detect any correlation or collinearity among independent variables. Further analyses were focused only on variables that significantly explained variation in the ptyctimous communities in the conditional effects space.

\section{Results}

\section{Richness and abundance of ptyctimous mites}

In total, 27 species from 5 families were found (Table 2). Species richness, calculated as species number per sample differed significantly among the localities (Fig. 4) $\left(X^{2}=11.81\right.$, $\mathrm{p}<0.05)$, and was highest in Eastern Norway, and lowest in Western Norway. Species richness did not differ significantly among the forest types and among the studied microhabitats.

Overall, 3,341 adult ptyctimous mites were collected in studied forests. These mites were found in $95 \%$ of extracted samples (out of a total of 147 samples collected). Their abundance differed significantly among the localities (Fig. 4) $\left(\mathrm{X}^{2}=31.20, \mathrm{p}<0.05\right)$. Multiple comparisons using the Median test $(\mathrm{P}=0.05)$ revealed significantly higher abundance of ptyctimous mites in Eastern Norway. In addition, the abundance of ptyctimous mites differed significantly among the forest types $\left(\mathrm{X}^{2}=28.17, \mathrm{p}<0.05\right)$, being higher in an old swamp than in a mixture of low-herb broadleaf and riparian forest, and in rich broadleaf forest (Fig. 5). It also differed among the studied microhabitats $\left(X^{2}=21.03, p<0.05\right)$, being significantly lower at higher section of tree trunks (1.5 $\mathrm{m}$ above ground) than in several other microhabitats (Fig. 6).

The most abundant species was Atropacarus (Atropacarus) striculus, which made nearly $30 \%$ of all ptyctimous mites collected, followed by Phthiracarus longulus, $P$. 


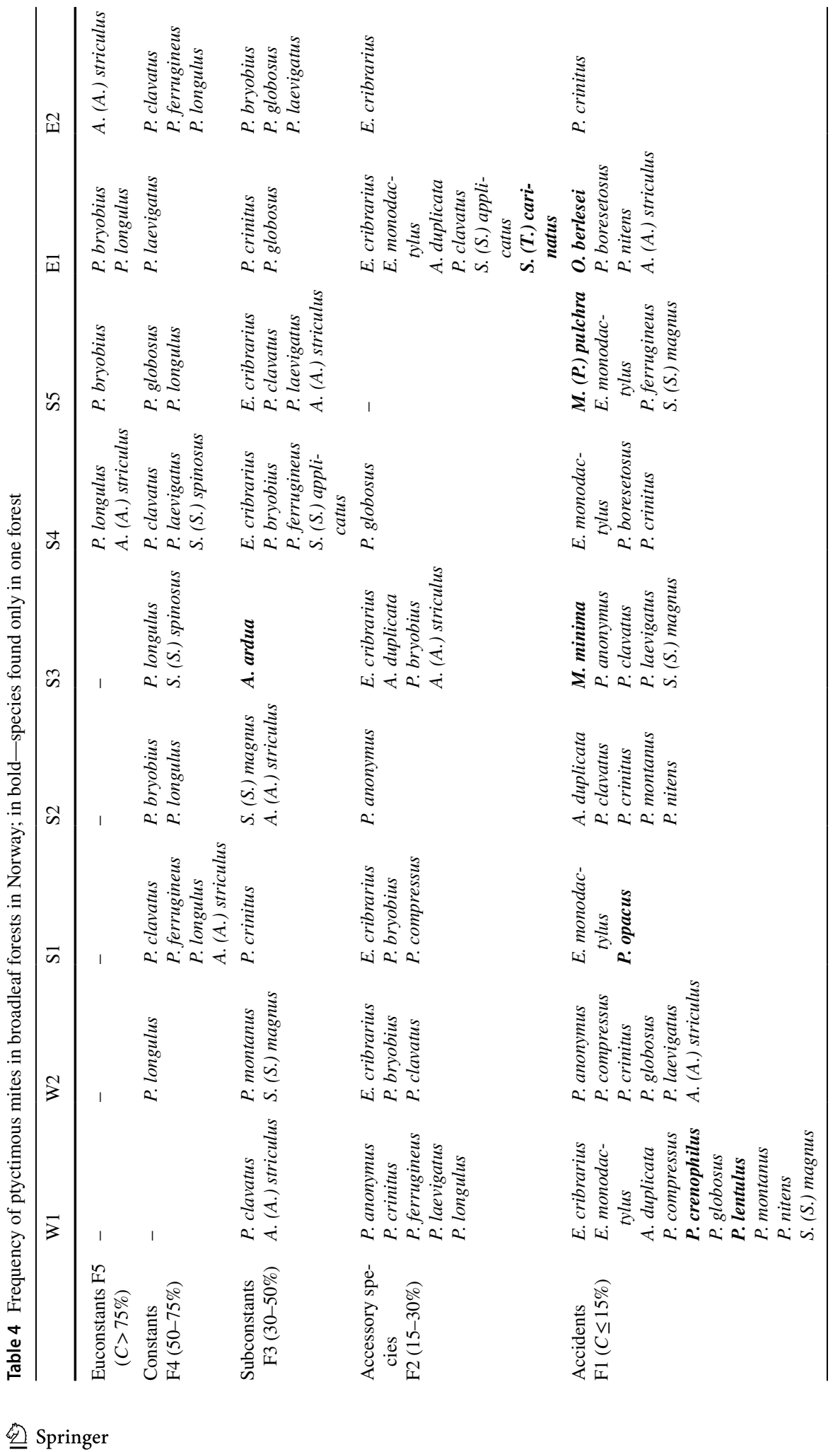


ferrugineus and P. clavatus (Table 2). Some species occurred in diverse microhabitats but were more abundant in some of them (Fig. 7). For example, A. (A.) striculus achieved the highest abundance in Sphagnum mosses on ground, Euphthiracarus cribrarius, E. monodactylus, Phthiracarus crinitus and P. longulus were most abundant in dead wood, while P. bryobius was abundant in lichens on tree twigs and in mosses growing on dead wood.

Three species out of the four most abundant were present in all forests [A. (A.) striculus, $P$. longulus and $P$. clavatus]. Several species were found exclusively in one forest (Table 3). More than half of species were found only in one type of habitat (Table 5) such as Sphagnum mosses on ground (Acrotritia ardua), other mosses on ground (Microtritia minima, Phthiracarus crenophilus, P. lentulus), lichens on tree twigs lying on ground (Oribotritia berlesei), mosses growing on tree trunk (Phthiracarus opacus), and in dead wood [Mesoplophora (Parplophora)] pulchra).

The dominance of $A$. (A.) striculus varied in different forests: e.g., in E2 it was superdominant (i.e., representing over $40 \%$ of ptyctimous mites), in three other forests (W1, S1, S3) it was eudominant (it constituted $20-40 \%$ of ptyctimous mites) and in two other forests (S2, S4) it was dominant (10-20\% of ptyctimous mites). The frequency of $A$. (A.) striculus was particularly high in forests S4 and E2, where it occurred in more than $75 \%$ of samples, but in others it occurred less often (Table 4). Another abundant species, $P$. longulus, was present in all forests with a high frequency.

One species representing family Mesoplophoridae, $M$. (P.) pulchra, is reported for the first time from Norway and from Fennoscandia. It was found (14 specimens) only in one sample of dead wood collected in Southern Norway. Nine additional species (Table 2) are also new records for Norway, including four that are recorded for the first time in Fennoscandia. Nearly all these species are regarded as silvicolous. Only one of these newly recorded species, $P$. ferrugineus, was numerous and frequent (it was found in $23 \%$ of samples with average abundance of nine specimens per sample), one another species, Phthiracarus anonymus was abundant but rare (it was found in $9 \%$ of samples with average abundance three specimens per sample), while others were sparse or few and rare or very rare (Tables 3, 4 and 6).

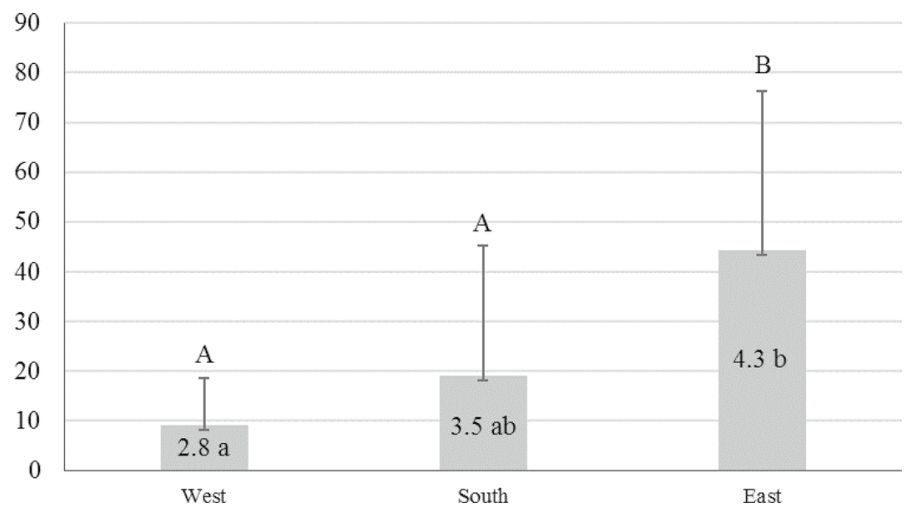

Fig. 4 Average abundance (bars) with standard deviation (whiskers), and average number of species per sample (inside bars) of ptyctimous mites in broadleaf forests in different parts of Norway; capital letters refer to abundance, small letters- to number of species per sample; different letters indicate significant differences at $p<0.05$ 


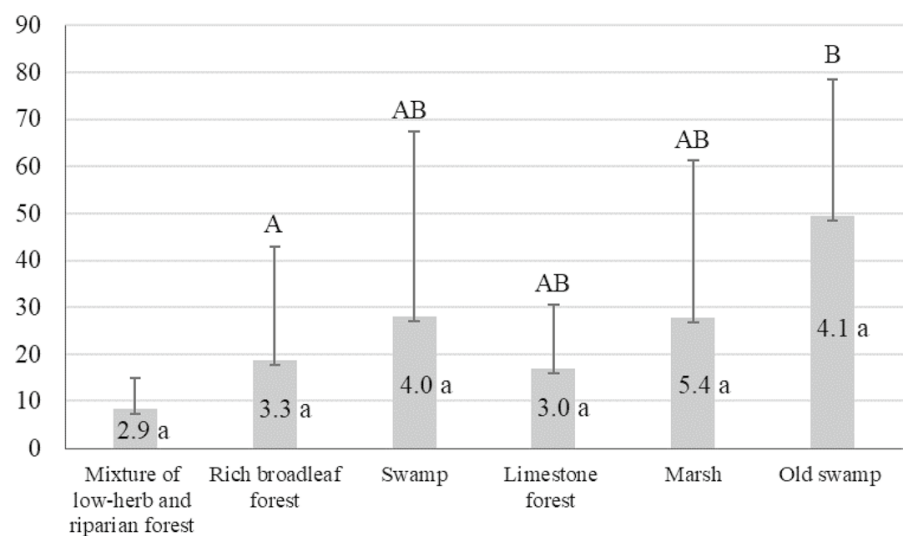

Fig. 5 Average abundance (bars) with standard deviation (whiskers), and average number of species per sample (inside bars) of ptyctimous mites in different types of broadleaf forests in Norway; capital letters refer to abundance, small letters- to number of species per sample; different letters indicate significant differences at $p<0.05$

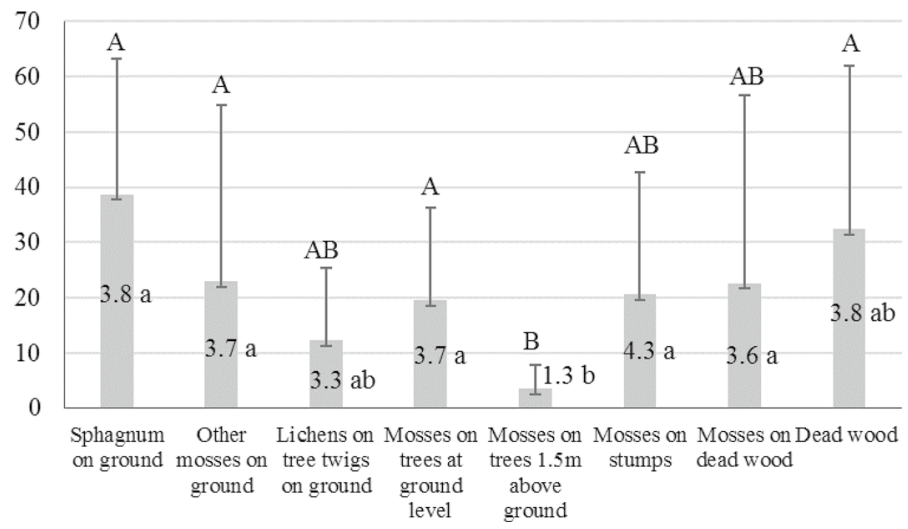

Fig. 6 Average abundance (bars) with standard deviation (whiskers), and average number of species per sample (in bars) of ptyctimous mites in microhabitats of broadleaf forests in Norway; capital letters refer to abundance, small letters - to number of species per sample; different letters indicate significant differences at $p<0.05$

\section{Factors affecting ptyctimous communities}

The forest type had the greatest effect (24.5\%) on the total variation of the ptyctimous communities when each variable was considered independently. Other variables had the following influence on the total variation: annual precipitation-14\%, mean annual temperature- $11.2 \%$, microhabitat- $13.4 \%$, forest wetness $-7.8 \%$, and regional locality-5\%; all significant at $\mathrm{p}<0.05$.

Considering all variables together, they accounted for $33.8 \%$ of the total variation. So, there is a clear interdependence among the variables, sharing great variation among them. Especially relevant is the co-variation between annual precipitation and temperature, and of those two factors to forest, and between annual precipitation and regional locality. To know which independent variables (factor levels) are the most significant, a forward selection 
was carried out (Table 7). It showed that all independent variables (except of the annual precipitation which is highly collinear to mean annual temperature) have some factor levels which are significant.

The effect of forest type on ptyctimous communities is seen in Fig. 8. In particular limestone forest was very different from other forests, with characteristic species A. ardua and M. minima - both found only in this forest (Table 3), and S. (S.) spinosus, which was particularly abundant and frequent there (Tables 3 and 4). All four rich broadleaf forests clustered together in the graph (Fig. 8), despite they were situated in different localities and in different vegetation and climatic zones.

Another factor explaining variation of the ptyctimous communities was forest wetness, and wet forest differed most from the others (Fig. 9). Its characteristic species were A. (A.) striculus and $P$. ferrugineus. Also, microhabitat was an important factor, and Sphagnum mosses differed most from other studied microhabitats, and characteristic species there was A. $\operatorname{ardua}$ (Fig. 10).

\section{Discussion}

\section{Richness and abundance of ptyctimous mites}

Species richness of ptyctimous mites was highest in Eastern Norway, and lowest in Western Norway, as already demonstrated for other arthropod groups (e.g., Lekander et al. 1977; Väisänen and Heliövaara 1994; Olsen et al. 2020). For example, in bark beetles, 47 species are known from the eastern part of the country, and only 14 from the western part (Lekander et al. 1977). Similarly, more than 90\% of all Heteroptera species of the Norwegian Red List for Species of 2006 occurred only in eastern and southern parts of Norway (Roth 2009). A similar west-east disparity is also typical for alpine vegetation in Norway (Moe 1995) and is explained by bedrock, climate and

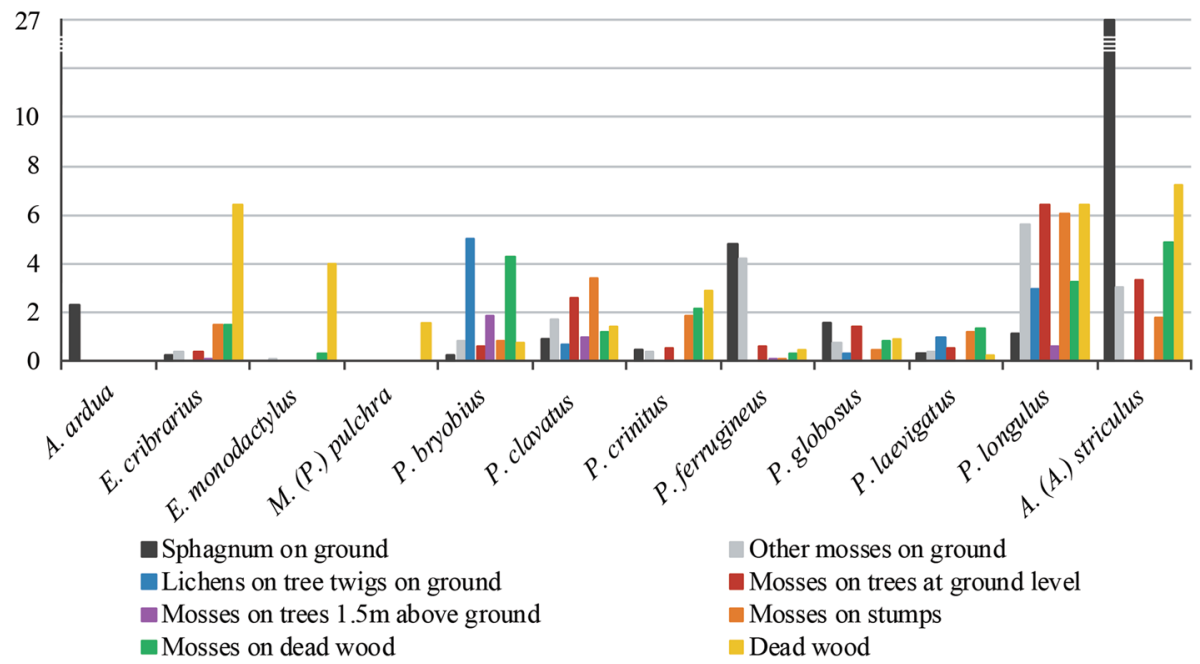

Fig. 7 Abundance of species in studied microhabitats of broadleaf forests; species with abundance lower than two individuals per $500 \mathrm{~cm}^{3}$ were excluded from the figure 
Table 5 Occurrence of ptyctimous mites in studied microhabitats; in bold—-species found only in one forest

\begin{tabular}{|c|c|}
\hline Microhabitat & Species \\
\hline Sphagnum mosses on ground & $\begin{array}{l}\text { E. cribrarius, } \text { A. ardua, } P \text {. bryobius, } \text { P. clavatus, } \text { P. crinitus, } \text { P. fer- } \\
\text { rugineus, } P \text {. globosus, } \\
\text { P. laevigatus, } \text { P. longulus, S. (S.) spinosus, A. (A.) striculus }\end{array}$ \\
\hline Other mosses on ground & 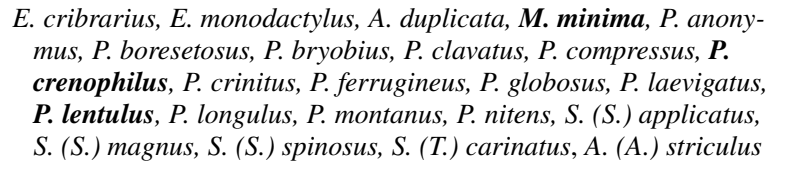 \\
\hline Lichens on tree twigs on ground & $\begin{array}{l}\text { O. berlesei, } P \text {. bryobius, } P \text {. clavatus, } P \text {. globosus, } P \text {. laevigatus, } P \text {. } \\
\text { longulus, } P \text {. nitens, } S . \text { (S.) applicatus, } S . \text { (T.) carinatus }\end{array}$ \\
\hline Mosses on trees at ground level & 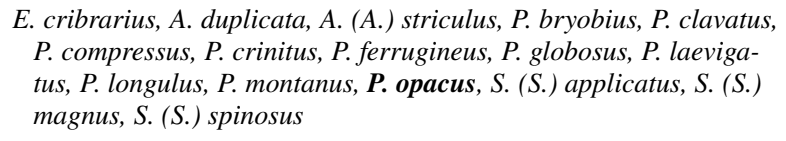 \\
\hline Mosses on trees $1.5 \mathrm{~m}$ above ground & $\begin{array}{l}\text { E. cribrarius, P. bryobius, P. clavatus, P. ferrugineus, } P \text {. longulus, } P \text {. } \\
\text { montanus }\end{array}$ \\
\hline Mosses on stumps & $\begin{array}{l}\text { E. cribrarius, } A \text {. duplicata, } P \text {. anonymus, } P \text {. bryobius, } P \text {. clavatus, } P \text {. } \\
\text { compressus, } P \text {. crinitus, } P \text {. ferrugineus, } P \text {. globosus, } P \text {. laevigatus, } \\
\text { P. lentulus, } P \text {. longulus, } P \text {. nitens, } S . \text { (S.) applicatus, } S \text {. (S.) magnus, } \\
\text { A. (A.) striculus }\end{array}$ \\
\hline Mosses on dead wood & $\begin{array}{l}\text { E. cribrarius, E. monodactylus, } P \text {. anonymus, } P \text {. boresetosus, } P \text {. } \\
\text { bryobius, } P \text {. clavatus, } P \text {. crinitus, } P \text {. ferrugineus, } P \text {. globosus, } P \text {. } \\
\text { laevigatus, } P \text {. longulus, } P \text {. montanus, } P \text {. nitens, } S \text {. (S.) applicatus, } S \text {. } \\
\text { (S.) magnus, } S \text {. (S.) spinosus, A. (A.) striculus }\end{array}$ \\
\hline Dead wood & $\begin{array}{l}\text { M. (P.) pulchra, E. cribrarius, E. monodactylus, } P \text {. bryobius, } P \text {. } \\
\text { clavatus, } P \text {. crinitus, } \text { P. ferrugineus, } \text { P. globosus, P. laevigatus, } P \text {. } \\
\text { longulus, A. (A.) striculus }\end{array}$ \\
\hline
\end{tabular}

glacial history. The colonization of Norway by mosses after the last glacial maximum, included three routes: western, southern, and eastern (e.g., Kyrkjeeide et al. 2014). The terrestrial route from the east allowed quicker immigration of species, but further dispersal has been limited by the Scandinavian Mountains.

The broadleaf forests selected for our studies turned out to be very rich in ptyctimous mites, adding one family and ten species new to the Norwegian fauna, and one family and four species, new to Fennoscandia. Broadleaf forests support the highest richness of ptyctimous mites as showed in Białowieża Primeval Forest in Poland (Niedbała et al. 2020). Based on our findings and earlier publications (Niedbała and Liu 2018; Seniczak et al. 2019a, c) ptyctimous mites are now represented in Norway by five families and 31 species. The number of ptyctimous mite species found in present study (27) was higher than reported in extensive studies from other parts of Europe (e.g., Erdmann et al. 2012; Corral-Hernández et al. 2016). Although those studies only included samples from the forest floor, the number of ptyctimous mite species collected from the forest floor of Norwegian broadleaf forests was also higher (24) than reported from Germany (9 species) or Spain (18 species). The number of species in our study was also higher than in Białowieża Primeval Forest (Poland), where only 22 ptyctimous species were recorded (Niedbała et al. 2020) from a much higher total number of samples (375 vs. 147 samples). Białowieża Primeval Forest is 
Table 6 Status of occurrence of ptyctimous mites in broadleaf forests (based on forest where species had highest dominance or frequency); in bold—-species found only in one forest

\begin{tabular}{|c|c|c|c|c|}
\hline & Very frequent (F5) & Frequent (F4-F3) & Rare (F2) & Very rare $(\mathrm{F} 1)$ \\
\hline Numerous (D6-D5) & $\begin{array}{l}\text { P. bryobius } \\
\text { P. longulus } \\
\text { A. (A.) striculus }\end{array}$ & $\begin{array}{l}\text { A. ardua } \\
\text { P. ferrugineus } \\
\text { P. globosus } \\
\text { S. (S.) spinosus }\end{array}$ & & \\
\hline Abundant (D4) & & $\begin{array}{l}\text { P. clavatus } \\
\text { P. crinitus } \\
\text { S. (S.) applicatus } \\
\text { S. (S.) magnus }\end{array}$ & P. anonymus & \\
\hline Sparse (D3-D2) & & $\begin{array}{l}\text { E. cribrarius } \\
\text { P. laevigatus } \\
\text { P. montanus }\end{array}$ & $\begin{array}{l}\text { E. monodactylus } \\
\text { A. duplicata } \\
\text { S. (T.) carinatus }\end{array}$ & $\begin{array}{l}\text { M. }(\boldsymbol{P} .) \text { pulchra } \\
\text { P. boresetosus } \\
\text { P. compressus } \\
\text { P. lentulus } \\
\text { P. nitens } \\
\text { P. opacus }\end{array}$ \\
\hline Few (D1) & & & & $\begin{array}{l}\text { M. minima } \\
\text { O. berlesei } \\
\text { P. crenophilus }\end{array}$ \\
\hline
\end{tabular}

Table 7 Forward selection results: conditional effects of independent variables at factor level in ptyctimous communities in broadleaf forests in Norway

\begin{tabular}{lllll}
\hline Independent variable & Explains \% & Contribution \% & Pseudo- $F$ & $p$ \\
\hline Forest, S3 & 5.9 & 17.4 & 8.6 & 0.001 \\
Forest wetness, wet & 5.7 & 17.0 & 8.9 & 0.001 \\
Microhabitat, Sphagnum on ground & 3.4 & 10.1 & 5.5 & 0.001 \\
Forest, S5 & 3.0 & 8.7 & 5.0 & 0.001 \\
Forest, E1 & 2.7 & 8.1 & 4.5 & 0.001 \\
Mean annual temperature, $6.4^{\circ} \mathrm{C}$ & 2.7 & 8.1 & 4.5 & 0.001 \\
Forest, S1 & 2.5 & 7.5 & 4.4 & 0.001 \\
Microhabitat, other mosses on ground & 2.1 & 6.3 & 3.8 & 0.001 \\
Microhabitat, dead wood & 1.6 & 4.9 & 3.0 & 0.012 \\
Forest, W1 & 1.4 & 4.1 & 2.5 & 0.004 \\
Mean annual temperature, $7.2{ }^{\circ} \mathrm{C}$ & 1.4 & 4.0 & 2.5 & 0.007 \\
Microhabitat, mosses on dead wood & 1.2 & 3.4 & 2.1 & 0.019 \\
Microhabitat, mosses on tree $1.5 \mathrm{~m}$ above ground & 1.0 & 3.0 & 1.9 & 0.042 \\
\hline
\end{tabular}

particularly valuable for its nature, being a world-known UNESCO World Heritage Site, and famous for its high biological diversity (Gutowski and Jaroszewicz 2001). Although a higher richness of ptyctimous mites found in the Norwegian study may be related to the larger and more diverse area of sampling compared to Białowieża, it confirms the unique character and high biological diversity of Norwegian broadleaf forests (Håpnes 2003; Bolger et al. 2018; Seniczak et al. 2019a).

The much higher abundance of ptyctimous mites in Eastern Norway is explained partly by the numerous occurrence of superdominant $A$. (A.) striculus in forest E2, 
Fig. 8 Results of canonical correspondence analysis (CCA) of ptyctimous communities and broadleaf forests in Norway; eigenvalues for Axis $1=0.4047$ and Axis $2=0.3602$ (both $13.33 \%)$; the graphs show 15 best-fitted species; variables are represented by red triangles (their size indicates the importance of a factor); forest abbreviations are explained in Table 1 and species names in Table 2

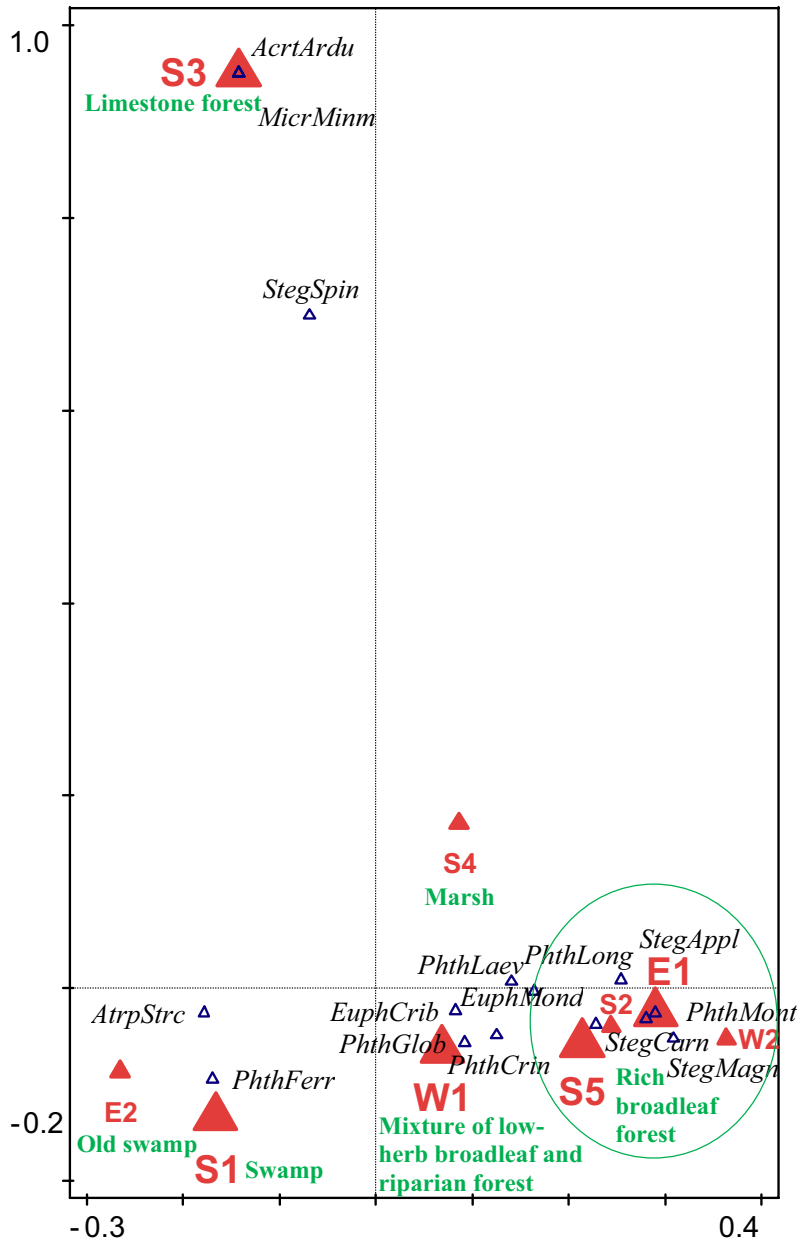

where forest floor was covered by Sphagnum mosses. Superdominant species are characteristic of extreme microhabitats (Seniczak 1978), like swamps or bogs (Seniczak et al. 2016). Atropacarus (A.) striculus may also occur in soils of fresh to wet forests, meadows and peatlands (Weigmann 2006; Niedbała 2011; Mumladze et al 2013; Seniczak et al. 2019b, c). It is also the most common and abundant ptyctimous mite in Finland (Penttinen and Huhta 2009) and in the Białowieża Primeval Forest in Poland (Niedbała et al. 2020). This species is semicosmopolitan (Niedbała and Liu 2018), and in Norway is found north to Svalbard, where it is the only representative of ptyctimous mites (Seniczak and Seniczak 2020; Seniczak et al. 2020).

As about other forests, where the abundance of ptyctimous mites differed significantly, the explanation seems more complex. It is known that the abundance of oribatid mites varies with the forest type, as indicated by our study, and seems related to the thickness of the litter layer. Moreover, abundance increases with the forest age (Erdmann et al. 2012). One forest in the east (E2), for example, had many old and large oak and lime trees that likely favoured high abundance of ptyctimous mites. In turn, forests in Western Norway had low densities of ptyctimous mites, that could be 
Fig. 9 Results of canonical correspondence analysis (CCA) of ptyctimous communities and wetness of broadleaf forests in Norway; eigenvalues for Axis $1=0.3131$ and Axis $2=0.1347$ (both $7.80 \%$ ); the graphs show the 15 best-fitted species; variables are represented by red triangles (their size indicates the importance of a factor); abbreviations of species names are explained in Table 2
Fig. 10 Results of canonical correspondence analysis (CCA) of ptyctimous communities and microhabitats of broadleaf forests in Norway; eigenvalues for Axis $1=0.3283$ and Axis $2=0.1740$ (both $8.75 \%$ ); the graphs show the 15 best-fitted species; variables are represented by red triangles (their size indicates the importance of a factor); abbreviations of species names are explained in Table 2
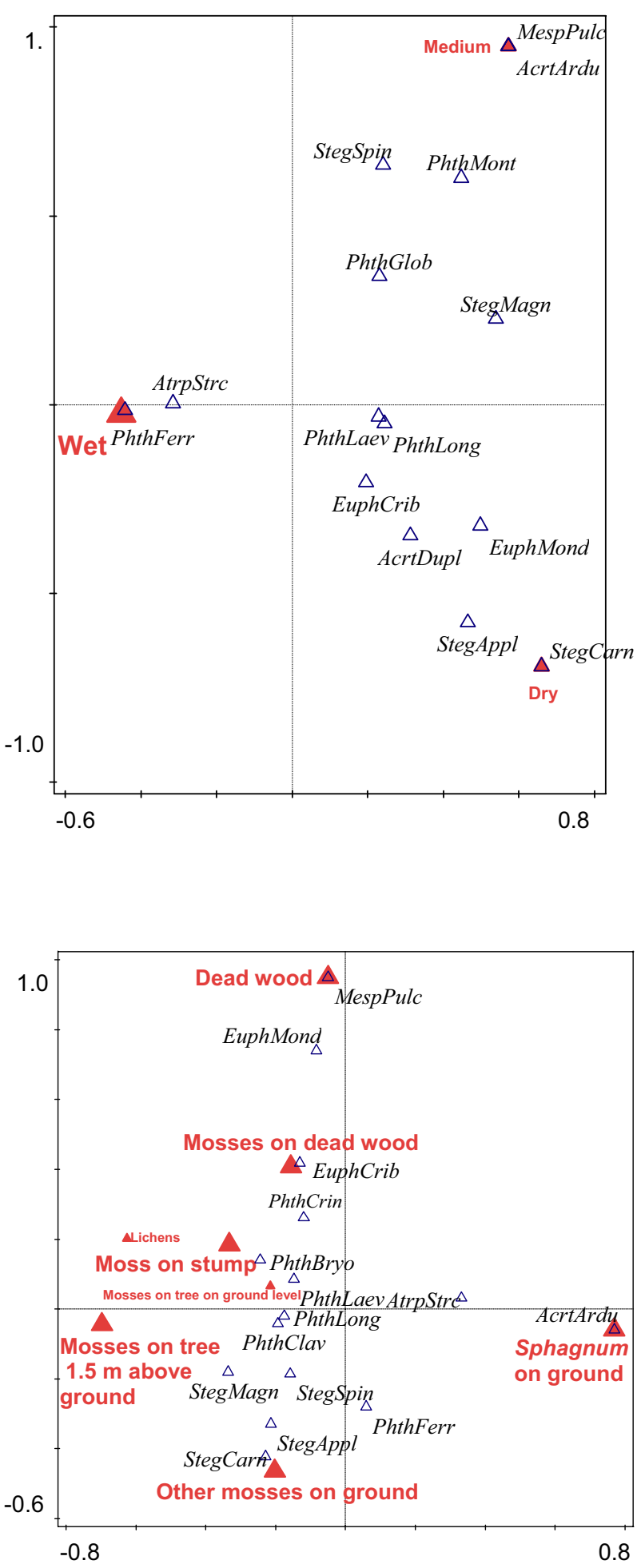
partially related to grazing and pruning activities in the past and in one forest (W1) we noted that grazing still continues. Grazing is affecting microhabitats of oribatid mites in many ways, usually decreasing their abundance (e.g., Erdmann et al. 2012; Pacek et al. 2020).

\section{Factors affecting ptyctimous communities}

The type of broadleaf forest had the greatest impact on variation of ptyctimous communities that is consistent with studies on mites in broadleaf forests in Ireland (Bolger et al. 2014) and Spain (Corral-Hernández et al. 2016). In contrast, oribatid communities from broadleaf forests in Germany were most affected by the regional locality (Erdmann et al. 2012). The difference between our results and those obtained by Erdmann et al. (2012) can be predominantly caused by the fact that ptyctimous mites are mostly xylophagous (Niedbała 2008), being thus particularly dependent on tree species, while the broader Oribatida represent diverse feeding groups, mainly in soil. Although the maximum distance of studied localities was similar in present study and in studies of Erdmann et al. (2012) ( 750 km), we studied coastal areas with mild climate and little yearly variation, in contrast to the stronger seasonality characterizing the continental areas studied in Germany.

Additionally, microhabitat was an important factor for ptyctimous mites, similarly like observed in Mesostigmata and Oribatida in Ireland (Bolger et al. 2014). Dead wood was particularly attractive to these mites, fostering high abundance and species richness. In mosses, the abundance of ptyctimous mites was only slightly lower but the number of species was only a third of that in dead wood. Also, in one forest studied earlier in Western Norway, ptyctimous mites were particularly abundant in dead wood (Seniczak et al. 2019a). The proportion of ptyctimous mite specimens among Oribatida was on average $3.5 \%$, but differed among microhabitats, being much higher in dead wood (30\%) and low in mosses growing on tree trunks and a stump (1\%). Since not all Phthiracaridae were identified to species level in that study, it is not possible to compare the richness of this group across microhabitats. In fact, Oribatida as a total are usually most abundant and species-rich in mosses (e.g., Skubała 2016; Seniczak et al. 2018, 2019a).

More than half of the species that are new to Norway turned out to be rare or very rare and were found in one forest and in one type of microhabitat. Most of these species were also few and rare in Białowieża (Niedbała et al. 2020). This supports the fact that diverse microhabitats in old growth forests support a peculiar oribatid fauna (Hansen 2000; Eissfeller et al. 2013; Murvanidze et al. 2016; Skubała 2016; Seniczak et al. 2019a) and therefore are very informative in biodiversity studies.

The main conclusion from this study is that broadleaf forests in Norway are very rich in ptyctimous mites - so they fully deserve recognition as biodiversity hotspot areas. This group of mites also reflects a well-known, but not well-explained, pattern that species richness increases from west to east across the Scandinavian mountain range. Accumulation of biodiversity data in various animal and plant groups, preferably with associated genetic data, will contribute to a better understanding and development of large-scale biodiversity modeling (e.g., Caruso et al. 2019). Such models will likely support the current view of a delayed fauna development west of the mountain range, a likely result of high-altitude barriers in the post-glacial Scandinavian biome.

Acknowledgements We are very grateful to two reviewers for helpful comments on the earlier version of the manuscript. 
Author contributions AS, SS, RH, BHJ planned the study, WN identified most mites, JCI carried out statistical analyses, and all authors contributed to the conception and participated in the interpretation of data and writing of the manuscript.

Funding Open access funding provided by University of Bergen (incl Haukeland University Hospital). This study was supported by the Norwegian Taxonomy Initiative (Grants No. 35-16, 70184237 and 6-20, 70184243) and by the Polish Ministry of Science and Higher Education "Regional Initiative of Excellence" in 2019-2022 (Grant No. 008/RID/2018/19).

Data availability https://doi.org/10.5061/dryad.np5hqbzs.

\section{Declarations}

Conflict of interest The authors have no conflicts of interest to declare that are relevant to the content of this article.

Open Access This article is licensed under a Creative Commons Attribution 4.0 International License, which permits use, sharing, adaptation, distribution and reproduction in any medium or format, as long as you give appropriate credit to the original author(s) and the source, provide a link to the Creative Commons licence, and indicate if changes were made. The images or other third party material in this article are included in the article's Creative Commons licence, unless indicated otherwise in a credit line to the material. If material is not included in the article's Creative Commons licence and your intended use is not permitted by statutory regulation or exceeds the permitted use, you will need to obtain permission directly from the copyright holder. To view a copy of this licence, visit http://creativecommons.org/licenses/by/4.0/.

\section{References}

Aune B (1993) Air temperature normals, normalperiod 1961-1990. Det Norske Meteorologiske Institutt Klima 2(93): 1-63

Beck L, Horak F, Woas S (2014) Zur Taxonomie der Gattung Phthiracarus Perty, 1841 (Acari, Oribatida) in Südwestdeutschland. Carolinea 72:109-132

Bolger T, Arroyo J, Kenny J, Caplice M (2014) Hierarchical analysis of mite community structures in Irish forests - a study of the relative contribution of location, forest type and microhabitat. Appl Soil Ecol 83:39-43. https://doi.org/10.1016/j.apsoil.2013.06.004

Bolger T, Devlin M, Seniczak A (2018) First records of ten species of Mesostigmata (Acari, Mesostigmata) added to the published Norwegian species list. Nor J Entomol 65:94-100

Caruso T, Schaefer I, Monson F, Keith AM (2019) Oribatid mites show how climate and latitudinal gradients in organic matter can drive large-scale biodiversity patterns of soil communities. J Biogeogr 46:611-620. https://doi.org/10.1111/jbi.13501

Corral-Hernández E, Balanzategui I, Iturrondobeitia JC (2016) Ecosystemic, climatic and temporal differences in oribatid communities (Acari: Oribatida) from forest soils. Exp Appl Acarol 69:389-401. https://doi.org/10.1007/s10493-016-0052-3

Eissfeller V, Langenbruch C, Jacob A, Maraun M, Scheu S (2013) Tree identity surpasses tree diversity in affecting the community structure of oribatid mites (Oribatida) of deciduous temperate forests. Soil Biol Biochem 63:154-162. https://doi.org/10.1016/j.soilbio.2013.03.024

Erdmann G, Scheu S, Maraun M (2012) Regional factors rather than forest type drive the community structure of soil living oribatid mites (Acari, Oribatida). Exp Appl Acarol 57(2):157-169. https://doi.org/ 10.1007/s10493-012-9546-9

Førland EJ (1993) Precipitation normals, normal period 1961-1990. Det Norske Meterologiske Institutt Klima 39(93):1-63

Górny M, Grüm L (1981) Metody stosowane w zoologii gleby. PWN, Warszawa

Gutowski JM, Jaroszewicz B (2001) Catalogue of the fauna of Białowieża Primeval Forest. Instytut Badawczy Leśnictwa, Warszawa.

Hågvar S (1998) Mites (Acari) developing inside decomposing spruce needles: Biology and effect on decomposition rate. Pedobiologia 42(4):358-377 
Hågvar S, Amundsen T (1981) Effects of liming and artificial acid rain on the mite (Acari) fauna in coniferous forest. Oikos 37:7-20

Hansen RA (2000) Effects of habitat complexity and composition on a diverse litter microarthropod assemblage. Ecology 81(4):1120-1132. https://doi.org/10.2307/177183

Håpnes A (2003) Background note: Natural forest heritage in Norway. WWF Norway.

Holtan D (2009) Kartlegging og verdisetting av naturtyper i Kvam. Kvam Herad og Fylkesmannen i Hordaland. MVA-rapport 2/2009, 1-103.

Huhta V, Räty M, Ahlroth P, Hänninen SM, Mattila J, Penttinen R, Rintala T (2005) Soil fauna of deciduous forests in central Finland. Memo Soc Fauna Flora Fenn 81(2):52-70

Meteorologisk Institutt, https://www.met.no accessed Feb 2021

Jongman RHG, ter Braak CJF, van Tongeren OFR (1995) Data analysis in community and landscape ecology. Cambridge University Press, Cambridge

Kyrkjeeide MO, Stenøien HK, Flatberg KI, Hassel K (2014) Glacial refugia and post-glacial colonization patterns in European bryophytes. Lindbergia 37:47-59

Lekander B, Bejer-Petersen B, Kangas E, Bakke A (1977) The distribution of bark beetles in the Nordic countries. Entomol Fenn 32:1-37

Łomnicki A (2010) Wprowadzenie do statystyki dla przyrodników. PWN, Warszawa

Moe B (1995) Studies of the alpine flora along an east-west gradient in central Western Norway. Nord J Bot 15(1):77-89

Moen A (1999) National Atlas of Norway: Vegetation. Norwegian Mapping Authorities, Hønefoss.

Mumladze L, Murvanidze M, Behan-Pelletier V (2013) Compositional patterns in Holarctic peat bog inhabiting oribatid mite (Acari: Oribatida) communities. Pedobiologia 56(1):41-48. https://doi.org/ 10.1016/j.pedobi.2012.10.001

Murvanidze M, Mumladze L, Arabuli T, Barjadze S, Salakaia M (2016) Oribatida diversity in different microhabitats of Mtirala National Park. J Acarol Soc Jpn 25(S1):35-49. https://doi.org/10.2300/ acari.25.Suppl_35

Niedbała W (1992) Phthiracaroidea (Acari, Oribatida). Systematic Studies. Państwowe Wydawnictwo Naukowe, Warszawa

Niedbała W (2008) Ptyctimous mites (Acari, Oribatida) of Poland. Fauna Poloniae, 242 pp. Vol. 3, Museum and Institute of Zoology, Polish Academy of Sciences, Warszawa.

Niedbała W (2011) Ptyctimous mites (Acari, Oribatida) of the Palearctic Region. Systematic Part Fauna Mundi 4:1-472

Niedbała W, Liu D (2018) Catalogue of ptyctimous mites (Acari, Oribatida) of the world. Zootaxa 4393:1-238

Niedbała W, Błoszyk J, Gutowski JM, Konwerski S, Napierała A (2020) A characteristic of a community of ptyctimous mites (Acari: Oribatida) in the Białowieża Primeval Forest, Central Europe. In: Błoszyk J, Napierała A (eds) Mites (Acari) of the Białowieża Primeval Forest. Wydawnictwo Kontekst, Poznan, pp 61-87.

Norwegian Ministry of the Environment (2011) Norway's Environmental Targets. https://www.regje ringen.no accessed 30 Mar 2019

Olsen SL, Hedger RD, Hendrichsen D, Dillinger B, Venter A, Evju M (2020) Hotspots for truede arter i Norge: karplanter, insekter og edderkoppdyr, sopp, lav og moser. NINA Temahefte 75 . Norsk institutt for naturforskning.

Pacek S, Seniczak S, Graczyk R, Chachaj B, Seniczak A (2020) Seasonal dynamics of mites (Acari) in pastures and meadows in Poland, with species analysis of Oribatida. Acarologia 60(4):668-683

Pande YD, Berthet P (1973) Studies on the food and feeding habits of soil Oribatei in a black pine plantation. Oecologia 12(4):413-426

Penttinen R, Huhta V (2009) Ptyctima (Acari, Oribatida) in various habitats in Finland. In: Sabelis MW, Bruin J (eds) Trends in Acarology, Proceedings of the 12th International Congress, Springer, Amsterdam, pp 167-170.

Roth S (2009) Die Wanzen Norwegens: Arten, Erfassungsstand und Rote Liste. Heteropteron 31:7-13

Sanders FH, Norton RA (2004) Anatomy and Function of the ptychoid defensive mechanism in the mite Euphthiracarus cooki (Acari, Oribatida). J Morphol 259:119-154. https://doi.org/10.1002/jmor. 10183

Schatz H (2015) Hornmilben (Acari, Oribatida) vom Fohramoos (Vorarlberg, Österreich). InaturaForschung online. Dornbirn 18:1-17

Seniczak S (1978) Stadia młodociane mechowców (Acari, Oribatei) jako istotny składnik zgrupowań tych roztoczy przetwarzających glebową substancję organiczną. Rozprawy UMK, Torun.

Seniczak A, Seniczak S (2020) Diversity of oribatid mites (Sarcoptiformes) in the Svalbard Archipelago: a historical overview. Zootaxa 4834(1):41-65 
Seniczak A, Seniczak S, Maraun M, Graczyk R, Mistrzak M (2016) Oribatid mite species numbers increase, densities decline and parthenogenetic species suffer during bog degradation. Exp Appl Acarol 68:409-428. https://doi.org/10.1007/s10493-016-0015-8

Seniczak S, Graczyk R, Seniczak A, Faleńczyk-Koziróg K, Kaczmarek S, Marquardt T (2018) Microhabitat preferences of Oribatida and Mesostigmata (Acari) inhabiting lowland beech forest in Poland and the trophic interactions between these mites. Eur J Soil Biol 87:25-32. https://doi.org/ 10.1016/j.ejsobi.2018.04.004

Seniczak A, Bolger T, Roth S, Seniczak S, Djursvoll P, Jordal BH (2019a) Diverse mite communities (Acari: Oribatida, Mesostigmata) from a broadleaf forest in western Norway. Ann Zool Fenn 56(1):121-136. https://doi.org/10.5735/086.056.0111

Seniczak A, Seniczak S, Graczyk R, Waldon-Rudzionek B, Nowicka A, Pacek S (2019b) Seasonal dynamics of oribatid mites (Acari, Oribatida) in a bog in Poland. Wetlands 39(4):853-864. https:// doi.org/10.1007/s13157-019-01125-2

Seniczak A, Seniczak S, Iturrondobeitia JC, Solhøy T, Flatberg KI (2019c) Diverse Sphagnum mosses support rich moss mite communities (Acari, Oribatida) in mires of western Norway. Wetlands 40:1339-1351. https://doi.org/10.1007/s13157-019-01236-w

Seniczak A, Seniczak S, Schwarzfeld MD, Coulson SJ, Gwiazdowicz DJ (2020) Diversity and distribution of mites (Acari: Ixodida, Mesostigmata, Trombidiformes, Sarcoptiformes) in the Svalbard archipelago. Diversity 12(9):323. https://doi.org/10.3390/d12090323

Skubała P (2016) Microhabitats and oribatid fauna: comparison of 2 sampling approaches. Biol Lett 53(1):31-47. https://doi.org/10.1515/biolet-2017-0005

Subías LS $(2004,2021)$ Listado sistemático, sinonímico y biogeográfico de los ácaros oribátidos (Acariformes, Oribatida) del mundo (excepto fósiles). Graellsia 60:3-305, actualized on http://bba.bioucm. es/cont/docs/RO_1.pdf. accessed 23 Mar 2021

Ter Braak, CJF (1988) CANOCO—a FORTRAN Program for Canonical Community Ordination by (Partial) (detrended) (Canonical) Correspondence Analysis, Principle Component Analysis and Redundancy Analysis. TNO Inst, Wageningen.

Thunes KH, Skarveit J, Gjerde I (2003) The canopy arthropods of old and mature pine Pinus sylvestris in Norway. Ecography 26:490-502. https://doi.org/10.1034/j.1600-0587.2003.03392.x

Thunes (et al. 44 author) KH (2004) The arthropod community of Scots pine (Pinus sylvestris L.) canopies in Norway. Entomol Fenn 15(2):65-90

Väisänen R, Heliövaara K (1994) Hot-spots of insect diversity in Northern Europe. Ann Zool Fenn 31:71-81

Weigmann G (2006) Hornmilben (Oribatida). Die Tierwelt Deutschlands. 520 pp. Vol. 76, Goecke and Evers, Keltern.

Weigmann G, Horak F, Franke K, Christian A (2015) Verbreitung und Ökologie der Hornmilben (Oribatida) in Deutschland. Senckenberg, Museum Für Naturkunde, Görlitz, Peckiana 10.

Publisher's Note Springer Nature remains neutral with regard to jurisdictional claims in published maps and institutional affiliations. 